\title{
Projections from the Rat Prefrontal Cortex to the Ventral Tegmental Area: Target Specificity in the Synaptic Associations with Mesoaccumbens and Mesocortical Neurons
}

\author{
David B. Carr and Susan R. Sesack \\ Departments of Neuroscience and Psychiatry, University of Pittsburgh, Pittsburgh, Pennsylvania 15260
}

\begin{abstract}
Excitatory projections from the prefrontal cortex (PFC) to the ventral tegmental area (VTA) play an important role in regulating the activity of VTA neurons and the extracellular levels of dopamine (DA) within forebrain regions. Previous investigations have demonstrated that PFC terminals synapse on the dendrites of DA and non-DA neurons in the VTA. However, the projection targets of these cells are not known. To address whether PFC afferents innervate different populations of VTA neurons that project to the nucleus accumbens (NAc) or to the PFC, a triple labeling method was used that combined peroxidase markers for anterograde and retrograde tract-tracing with pre-embedding immunogold-silver labeling for either tyrosine hydroxylase $(\mathrm{TH})$ or GABA. Within the VTA, PFC terminals formed asymmetric synapses onto dendritic shafts that were immunoreactive for either TH or GABA. PFC terminals also synapsed on VTA dendrites that were retrogradely labeled from
\end{abstract}

the NAc or the PFC. Dendrites retrogradely labeled from the NAc and postsynaptic to PFC afferents were sometimes immunoreactive for GABA but were never TH-labeled. Conversely, dendrites retrogradely labeled from the PFC and postsynaptic to PFC afferents were sometimes immunoreactive for TH but were never GABA-labeled. These results provide the first demonstration of PFC afferents synapsing on identified cell populations in the VTA and indicate a considerable degree of specificity in the targets of the PFC projection. The unexpected finding of selective PFC synaptic input to GABA-containing mesoaccumbens neurons and DA-containing mesocortical neurons suggests novel mechanisms through which the PFC can influence the activity of ascending DA and GABA projections.

Key words: dopamine; GABA; nucleus accumbens; prelimbic cortex; infralimbic cortex; ultrastructure
Ascending projections of midbrain dopamine (DA) neurons to the nucleus accumbens (NAc) and prefrontal cortex (PFC) play important roles in motivation, reward, and cognitive functions. Extracellular DA levels within these regions are characterized by a tonic basal concentration, on which phasic increases in DA levels occur in response to behaviorally relevant stimuli (Finlay et al., 1995; Westerink, 1995; Wilson et al., 1995; Bassareo and Di Chiara, 1997; Rebec et al., 1997). These phasic increases in extracellular DA are likely caused by increased single spike and burst firing of midbrain DA neurons (Streckler and Jacobs, 1987; Schultz et al., 1997). Burst firing is especially associated with enhanced DA release from terminals (Gonon, 1988; Bean and Roth, 1991) and is critically dependent on afferent input, because DA neurons do not exhibit this firing pattern in vitro (Grace, 1987, 1988). Thus, determining the sources of afferent input that are responsible for the generation of burst firing is crucial in understanding the function of ascending DA systems. Burst firing in DA neurons is dependent, at least in part, on glutamate input, because blockade of glutamate receptors suppresses this activity pattern in these cells (Grenhoff et al., 1988; Charlety et al., 1991;

\footnotetext{
Received Dec. 1, 1999; revised Feb. 23, 2000; accepted Feb. 25, 2000.

This work was supported by United States Public Health Service Grant MH50314 (S.R.S.), a National Alliance for Research on Schizophrenia and Depression Independent Investigator Award (S.R.S.), and a Scottish Rite Dissertation Fellowship (D.B.C.). We thank Dr. J. Patrick Card for sharing his extensive knowledge and technical expertise concerning the use of pseudorabies virus and also Dr. L.W. Enquist (Princeton University) for generously supplying PRV and anti-PRV antiserum.

Correspondence should be addressed to Dr. Susan R. Sesack, Department of Neuroscience, 446 Crawford Hall, University of Pittsburgh, Pittsburgh, PA 15260. E-mail: Sesack@bns.pitt.edu.

Copyright (C) 2000 Society for Neuroscience $\quad 0270-6474 / 00 / 203864-10 \$ 15.00 / 0$
}

Overton and Clark, 1992; Chergui et al., 1993). One of the principal glutamate inputs to the ventral tegmental area (VTA) arises from the PFC (Christie et al., 1985; Sesack et al., 1989; Hurley et al., 1991; Sesack and Pickel, 1992; Lu et al., 1997). Moreover, PFC stimulation increases burst firing of DA neurons (Gariano and Groves, 1988; Murase et al., 1993; Tong et al., 1996), whereas inactivation of the PFC produces the opposite effect (Svensson and Tung, 1989; Murase et al., 1993). These effects may be mediated by the known monosynaptic projection from the PFC to DA neurons within the VTA (Sesack and Pickel, 1992).

The efferent targets of DA neurons that receive PFC input are not known. PFC afferents may target DA neurons that project to the NAc or those that project back to the PFC, because there is substantial overlap between the distribution of PFC terminals and the soma and dendrites of both mesoaccumbens and mesoprefrontal neurons within the VTA (Swanson, 1982; Sesack et al., 1989; Hurley et al., 1991; Sesack and Pickel, 1992). In addition, PFC stimulation produces excitatory responses in mesocortical or mesoaccumbens neurons that exhibit the physiological characteristics of DA cells (Thierry et al., 1979; Gariano and Groves, 1988). Neurochemical studies also indicate that PFC afferents target the DA cell populations that project to the NAc or to the PFC. Stimulation of the PFC increases levels of extracellular DA within the NAc (Murase et al., 1993; Taber and Fibiger, 1995; Taber et al., 1995; Karreman and Moghaddam, 1996), an effect that is blocked by infusion of glutamate antagonists into the VTA but not into the NAc (Taber and Fibiger, 1995; Taber et al., 1995; Karreman and Moghaddam, 1996). Inactivation of the PFC produces the opposite response (Murase et al., 1993), indicating a 
role of the PFC in the regulation of tonic levels of NAc DA. Stimulation of the PFC by local infusion of glutamate agonists also increases DA levels within the PFC (Jedema and Moghaddam, 1996), whereas glutamate antagonist infusion has the opposite effect (Takahata and Moghaddam, 1998). These effects may be attributable to changes in the activity of PFC neurons that project to mesoprefrontal DA cells, although mechanisms that are local to the cortex cannot be excluded.

Finally, in addition to the extensively studied DA projections of the VTA, recent studies have also demonstrated that GABAcontaining neurons project from the VTA to both the NAc (Van Bockstaele and Pickel, 1995) and to the PFC (Carr and Sesack, 2000). It is not known if these GABA-containing projection systems receive synaptic input from the PFC. However, both anatomical (Sesack and Pickel, 1992) and electrophysiological (Tong et al., 1998) studies have demonstrated monosynaptic contacts of PFC afferents onto non-DA neurons in the VTA. Thus, both GABA mesoaccumbens and mesocortical neurons may receive PFC synaptic input.

In this study, we have combined anterograde and retrograde tract tracing with immunocytochemistry and electron microscopy in a triple-labeling approach to examine the projections and neurochemical phenotypes of VTA neurons that receive synaptic contacts from PFC terminals.

\section{MATERIALS AND METHODS}

Tracer injection and immunocytochemical processing. Five adult male Sprague Dawley rats, anesthetized with chloral hydrate $(420 \mathrm{mg} / \mathrm{kg}$, i.p.), received bilateral injections of the anterograde tracer biotinylated dextran amine (BDA) into the medial $\mathrm{PFC}$ and the retrograde tracer FluoroGold (FG; Fluorochrome, Englewood, CO) into the NAc. Four rats received combined injections of $\mathrm{BDA}$ and $\mathrm{FG}$ into the PFC. BDA (10,000 MW; Molecular Probes, Eugene, OR) was dissolved as a $10 \%$ solution in $10 \mathrm{~mm}$ sodium phosphate buffer, $\mathrm{pH} 7.4$, and injected into the PFC via glass micropipettes using a controlled pressure device (PicoPump; World Precision Instruments). The coordinates for bilateral PFC injections were $3.0 \mathrm{~mm}$ anterior to bregma, $0.7 \mathrm{~mm}$ lateral to the midline, and 3.5 and $4.5 \mathrm{~mm}$ ventral to the skull surface, according to the atlas of Paxinos and Watson (1986). Approximately $100 \mathrm{nl}$ of BDA was injected at each of the four sites at a rate of $10 \mathrm{nl} / \mathrm{min}$. FG was dissolved as a $1 \%$ solution in $100 \mathrm{~mm}$ cacodylate buffer and injected into the NAc via iontophoresis to minimize tissue damage and potential uptake by fibers of passage (Pieribone and Aston-Jones, 1988). The coordinates for bilateral NAc injection were $1.7 \mathrm{~mm}$ anterior to bregma, $3.4 \mathrm{~mm}$ lateral to the midline, and 7.3 and $6.8 \mathrm{~mm}$ ventral to the skull surface. FG was iontophoretically injected ( $+5 \mathrm{~mA}$ pulsed $10 \mathrm{sec}$ on/off) for $20 \mathrm{~min}$ at each of the four locations through glass micropipettes lowered at a $15^{\circ}$ angle in the coronal plane. For FG injections into the PFC, the tracer was pressure-injected using the same methods and coordinates as BDA injections, but using separate micropipettes.

After a 5-7 day survival period, animals were deeply anesthetized with Nembutal $(100 \mathrm{mg} / \mathrm{kg}$, i.p) and perfused with $10 \mathrm{ml}$ of $0.9 \%$ saline containing $1000 \mathrm{U} / \mathrm{ml}$ heparin, followed by $50 \mathrm{ml}$ of $3.75 \%$ acrolein and $2 \%$ paraformaldehyde and $400 \mathrm{ml}$ of $2 \%$ paraformaldehyde in $0.1 \mathrm{M}$ phosphate buffer (PB), pH 7.4 . The brains were removed, and 4-6 mm coronal blocks containing the PFC, NAc, and VTA were post-fixed in $2 \%$ paraformaldehyde for $45 \mathrm{~min}$. Vibratome $(50 \mu \mathrm{m})$ sections from these blocks were collected in PB and incubated in 1\% sodium borohydride in PB to enhance immunocytochemical labeling (Leranth and Pickel, 1989).

A dual-labeling method was used in which PFC terminals anterogradely labeled with BDA and mesoaccumbens or mesocortical neurons retrogradely labeled with FG were visualized by peroxidase immunocytochemistry, whereas the neurochemical phenotype of retrogradely labeled neurons was revealed by pre-embedding immunogold labeling for either tyrosine hydroxylase (TH) or GABA. Vibratome sections were incubated for $30 \mathrm{~min}$ in blocking solution containing 3\% normal goat serum and $1 \%$ bovine serum albumin in $0.1 \mathrm{~m}$ Tris-buffered saline (TBS), $\mathrm{pH}$ 7.6. To enhance antibody penetration, blocking solution contained Triton X-100 (Sigma, St. Louis, MO) at $0.04 \%$ for electron microscopic examination or $0.2 \%$ for light microscopy. Sections were then incubated for $12-15 \mathrm{hr}$ in blocking solution containing polyclonal antiserum raised in rabbit against FG (1:4000; Chemicon, Temecula, CA) and monoclonal antibody raised in mouse against either $\mathrm{TH}(1: 5000$; Chemicon) or GABA (1:1000; Sigma).

For peroxidase localization of BDA and FG, sections were incubated for $30 \mathrm{~min}$ in biotinylated goat anti-rabbit antiserum (1:400; Vector Laboratories, Burlingame, CA) diluted in blocking solution. After several rinses in TBS, sections were incubated for $30 \mathrm{~min}$ in avidin-biotin peroxidase complex (1:200; Vectastain Elite kit; Vector Laboratories) in TBS. The peroxidase reaction was visualized by incubating the sections in $0.022 \%$ diaminobenzidine and $0.003 \%$ hydrogen peroxide in TBS for 2-4 min. The peroxidase reaction was terminated by several rinses in TBS. For immunogold localization of TH or GABA, sections were incubated for $30 \mathrm{~min}$ in blocking solution containing $0.8 \%$ bovine serum albumin and $0.1 \%$ fish gelatin in $10 \mathrm{~mm}$ PBS, $\mathrm{pH}$ 7.4. Sections were then incubated in blocking solution containing goat anti-mouse antiserum conjugated to $1 \mathrm{~nm}$ gold particles (1:50; Amersham, Arlington Heights, IL). After several rinses in blocking solution and PBS, the size of the gold particles was subsequently enhanced by incubation in silver solution (Amersham) for 5-7 min.

Sections for light microscopy were mounted on glass slides, dehydrated, and coverslipped. Sections for electron microscopic examination were post-fixed for $1 \mathrm{hr}$ in $2 \%$ osmium tetroxide in PB, dehydrated through successive alcohols and propylene oxide, and embedded in Epon (EM bed 812; Electron Microscopy Sciences). Sections were mounted on Epon blocks, and ultrathin sections were taken from the outer surface of the tissue and collected on copper mesh grids. Sections were counterstained with uranyl acetate and lead citrate and examined with a Zeiss 902 transmission electron microscope.

Pseudorabies virus-Bartha strain injection. Although FG extensively labels the dendritic tree of VTA neurons, it is sometimes confined to lysosomes within retrogradely labeled cells (Carr and Sesack, 2000). Thus, some of the dendrites of retrogradely labeled neurons may have been misclassified as unlabeled. Therefore, to confirm the results obtained with retrograde transport of FG from the NAc, additional experiments were performed in which pseudorabies virus-Bartha strain (PRV) was used to retrogradely label mesoaccumbens neurons. PRV produces extensive labeling within infected neurons, with no evidence of anterograde transport or uptake by fibers of passage (O'Donnell et al., 1997; Card et al., 1998; Carr et al., 1999). BDA was injected into the PFC of three male Sprague Dawley rats as described above. After a 5 d survival period, PRV injection was performed as described previously (Carr et al., 1999). Briefly, $100 \mathrm{nl}$ of PRV $\left(1.4 \times 10^{9} \mathrm{pfu} / \mathrm{ml}\right)$ was stereotaxically injected into the medial NAc of three male rats. After a $36 \mathrm{hr}$ survival period, the animals were killed, and the tissue was processed for electron microscopic examination as described above, substituting polyclonal antiserum raised in rabbit against PRV (1:10,000; gift of Dr. L.W. Enquist) for the anti-FG antiserum in the primary antibody step. This postinoculation survival period was chosen based on results from preliminary studies that this time period produces maximal labeling of first-order neurons without significant second-order infection (Carr et al., 1999) (P. O'Donnell, D. Carr, and J. Card unpublished observations). This protocol has been used extensively to determine the time course of neuronal infection in a variety of central systems (O'Donnell et al., 1997; Card et al., 1998; Carr et al., 1999; Leak et al., 1999).

Ultrastructural analysis. Ultrathin sections were taken from the outer surface of Vibratome sections through the parabrachial and paranigral regions of the anterior VTA. Within single, nonconsecutive thin sections, tissue contained within grid squares (boundaries of the grid mesh, 3025 $\mu \mathrm{m}^{2}$ ) along the Epon-tissue interface was examined at a magnification of $12,000 \times$. All synaptic contacts of BDA-labeled terminals were photographed at a magnification of $12,000-20,000 \times$. In animals receiving FG injections into the NAc, $1,104,125 \mu \mathrm{m}^{2}$ of tissue was examined from TH-labeled sections and $828,850 \mu \mathrm{m}^{2}$ from GABA-labeled sections. In animals receiving FG injections into the PFC, 1,022,450 $\mu \mathrm{m}^{2}$ of tissue was examined from TH-labeled sections and 1,016,400 $\mathrm{mm}^{2}$ from GABAlabeled sections. In animals receiving NAc PRV injections, 553,575 $\mu \mathrm{m}^{2}$ of tissue was examined from TH-labeled sections and $463,780 \mu \mathrm{m}^{2}$ from GABA-labeled sections. To reduce false-negative results caused by inadequate antibody penetration, only those areas at the surface of the tissue (Epon-tissue interface) where antibody penetration is maximal were examined. In addition, only micrographs that contained both peroxidase and gold markers within the same $32.5 \mu \mathrm{m}^{2}$ area (area contained within a single micrograph taken at $12,000 \times$ magnification) were analyzed. 

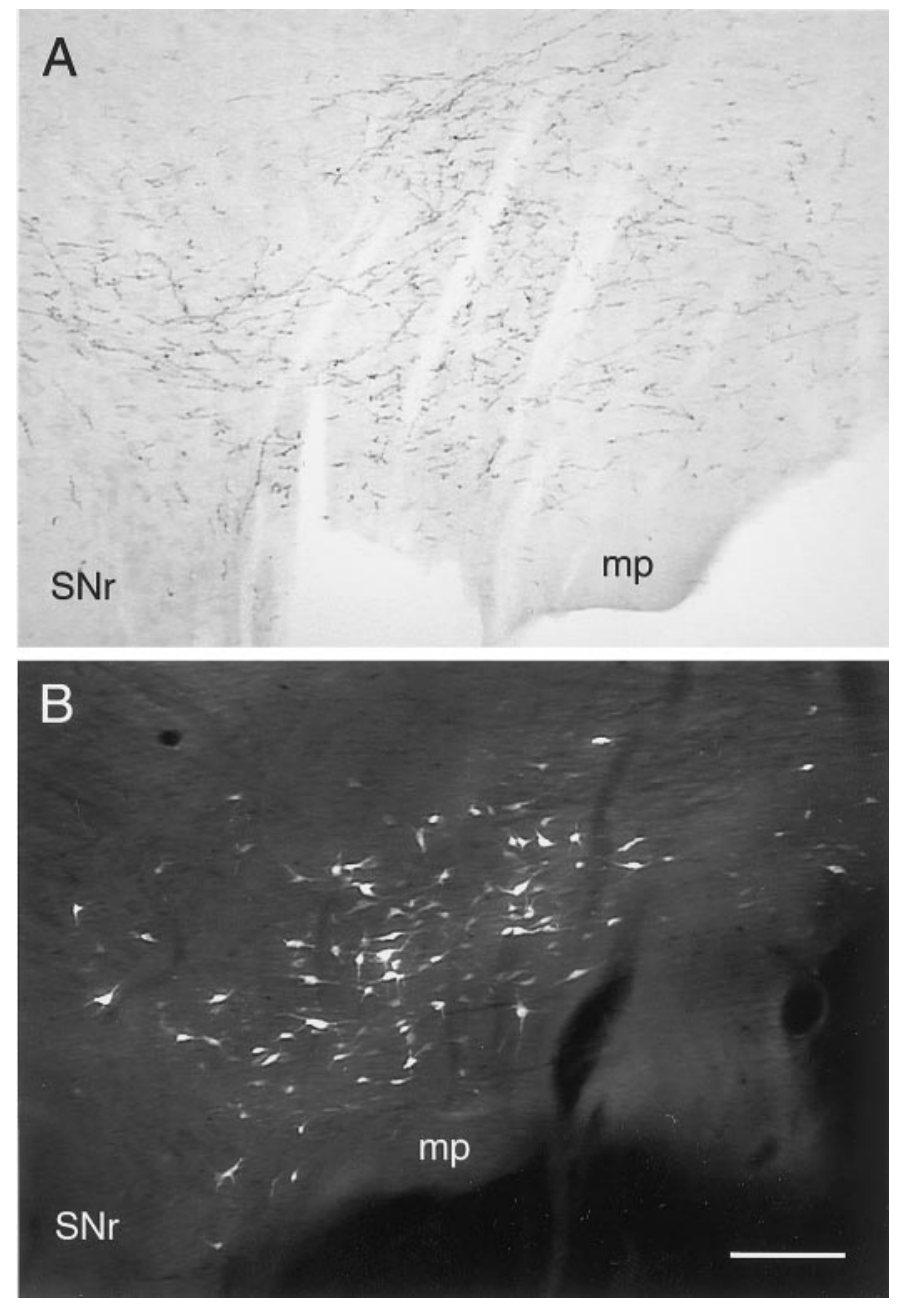

Figure 1. Light micrographs of coronal sections through the rat VTA showing the overlap of the somatodendritic field of mesoaccumbens neurons and PFC afferents. $A$, Bright-field micrograph showing the distribution of axons and terminals after injection of BDA into the medial PFC. $B$, Fluorescence micrograph displaying the distribution and extent of labeling of VTA neurons after an injection of FluoroGold into the medial NAc. $S N r$, Substantia nigra, zona reticulata; $m p$, mammilary peduncle. Medial is to the right. Scale bar, $140 \mu \mathrm{m}$.

Neuronal elements were identified in electron micrographs according to the criteria described by Peters et al. (1991). Neuronal somata were identified by the presence of a nucleus. Dendrites exhibited densities postsynaptic to axon terminals and contained mitochondria, microtubules, and/or rough endoplasmic reticulum. Axon terminals had crosssectional diameters of at least $0.2 \mu \mathrm{m}$ and contained numerous synaptic vesicles. Asymmetric synapses (Gray's type 1; Gray, 1959) exhibited thickened postsynaptic densities, whereas symmetric synapses (Gray's type II) had thin postsynaptic densities.

\section{RESULTS}

\section{Light-microscopic observations}

Within the PFC, BDA injections were centered in the prelimbic and infralimbic cortices, but also extended dorsally into the anterior cingulate cortex. Within the VTA, BDA-labeled axons were distributed throughout the parabrachial and paranigral divisions (Fig. 1A). No somatodendritic BDA labeling was observed, consistent with a purely anterograde transport of the tracer in this system. In those animals receiving FG injections into the PFC, the spread of these injections typically encompassed the same area as BDA labeling. Injections of either FG or
PRV into the NAc were centered in the medial portion of this nucleus, including both the core and shell subdivisions. Within the VTA, labeling for either FG or PRV was extensively distributed within retrogradely labeled neurons extending into the proximal and distal portions of the dendrites (Fig. 1B). There was extensive overlap of the terminal field of BDA-labeled axons with the somata and dendrites of VTA neurons retrogradely labeled from either the NAc (Fig. 1B) or PFC (data not shown).

\section{Electron microscopy}

Relationship between BDA-labeled terminals and $\mathrm{TH}$ - and $G A B A$-labeled dendrites

Within the rostral VTA, BDA labeling was confined to terminals and preterminal axons. No somatodendritic BDA labeling was observed, consistent with light-microscopic observations. BDAlabeled terminals (Fig. 2; see Figs. 4-6) exhibited morphological features consistent with previous observations of PFC terminals within the VTA (Sesack and Pickel, 1992). These terminals were sparsely distributed, requiring examination of a large area of tissue to obtain a reasonable sample of BDA-labeled synaptic terminals in each experimental condition (see Materials and Methods). Many BDA-labeled axons were of small diameter, contained few synaptic vesicles, and did not form synaptic contacts when examined in serial sections. These profiles are probably PFC axons passing through the VTA to more caudal targets. When BDA-labeled terminals were observed to form distinct synaptic contacts, these were exclusively of the asymmetric axodendritic type.

In VTA tissue labeled for TH, gold-silver immunolabeling was observed within neuronal somata as well as in large- and smallcaliber dendritic processes. Within this tissue, 37\% (39 of 105) of BDA-labeled terminals formed asymmetric synapses onto dendrites containing gold-silver labeling for TH (Fig. 2A, Table 1). In tissue labeled for GABA, the distribution of gold-silver labeling was more broad, being observed in axon terminals forming symmetric synaptic contacts, as well as in neuronal somata and dendrites. Within this GABA-labeled tissue, 37\% (35 of 95) of BDA-labeled terminals formed synapses onto dendrites containing gold-silver labeling for GABA (Fig. 2B, Table 1).

\section{Relationship between BDA-labeled terminals and retrogradely labeled mesoaccumbens dendrites}

Within the VTA, immunoperoxidase labeling for FG or PRV retrogradely transported from the NAc was diffusely distributed within neuronal somata as well as in large- and small-caliber dendritic profiles (Figs. 3-5). Occasionally, immunoreactivity for FG was confined to lysosomes (Fig. 4A). Peroxidase immunoreactivity for FG or PRV was distinct from gold-silver labeling for TH or GABA, and profiles dually labeled with both peroxidase and gold-silver markers were readily distinguishable from those singly labeled for either marker alone (Fig. 3). No significant differences were observed in data obtained in animals receiving either PRV or FG injections into the NAc, so data from both groups was pooled together. In both $\mathrm{TH}$ - and GABA-labeled tissue from animals receiving injections of either tracer into the NAc, the majority of BDA-labeled terminals formed synaptic contacts onto unlabeled dendrites (Fig. 4A). In TH-labeled tissue from these animals, BDA-labeled terminals synapsed onto dendrites containing only peroxidase labeling for FG or PRV (Fig. $4 B$ ) and onto dendrites containing only gold-silver labeling for $\mathrm{TH}$, but not onto dendrites containing both markers. BDAlabeled terminals were often observed in the same area of neu- 

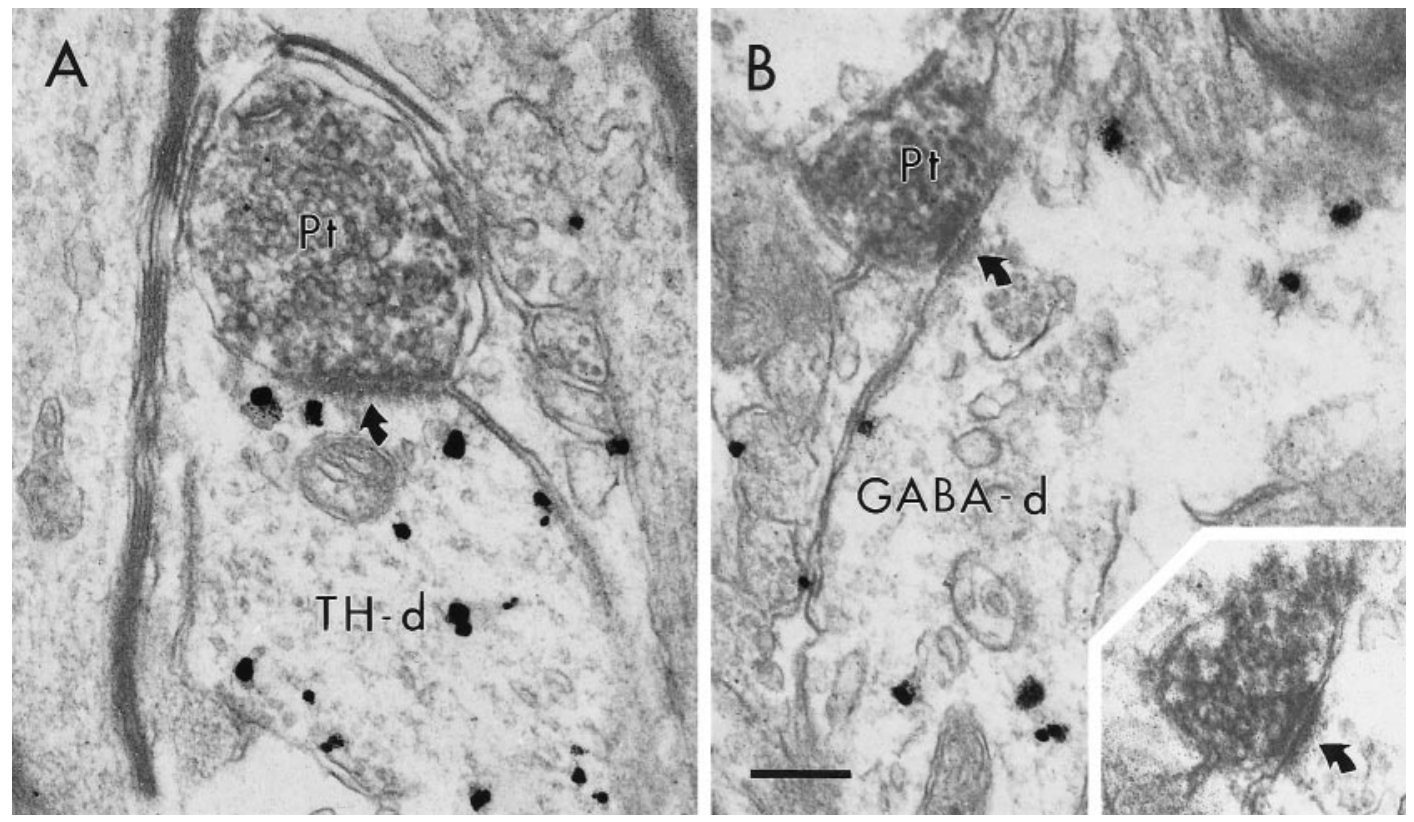

Figure 2. Electron micrographs showing synaptic contacts (curved arrows) of BDA-labeled PFC terminals (Pt) onto dendrites containing immunogoldsilver labeling for TH $(A, T H-d)$ or GABA $(B, G A B A-d)$. In $B$, the synapse formed by the Pt on the GABA-d is also prominent in an adjacent section (inset). Scale bar, $0.25 \mu \mathrm{m}$.

\begin{tabular}{lll}
\hline Table 1. Synaptic contacts of BDA-labeled PFC terminals within the rat VTA & \\
& $\begin{array}{l}\text { Retrograde labeling } \\
\text { from the NAc }\end{array}$ & $\begin{array}{l}\text { Retrograde labeling } \\
\text { from the PFC }\end{array}$ \\
\hline $\begin{array}{l}\text { TH-labeled tissue } \\
\text { BDA-labeled terminals forming synapses }\end{array}$ & 52 & 53 \\
$\quad$ onto unlabeled dendrites & $28(54 \%)$ & $34(64 \%)$ \\
$\quad$ onto dendrites labeled for TH only & $20(38 \%)$ & $14(26 \%)$ \\
$\quad$ onto dendrites labeled for FG/PRV only & $4(8 \%)$ & $0(0 \%)$ \\
onto dendrites labeled for both TH and FG/PRV & $0(0 \%)$ & $5(9 \%)$ \\
GABA-labeled tissue & 46 & 49 \\
BDA-labeled terminals forming synapses & $29(63 \%)$ & $28(57 \%)$ \\
$\quad$ onto unlabeled dendrites & $12(26 \%)$ & $18(37 \%)$ \\
onto dendrites labeled for GABA only & $0(0 \%)$ & $3(6 \%)$ \\
onto dendrites labeled for FG/PRV only & $5(11 \%)$ & $0(0 \%)$ \\
onto dendrites labeled for both GABA and FG/PRV & 5 & \\
\hline
\end{tabular}

ropil as dendrites dually labeled for $\mathrm{TH}$ and FG or PRV, but in every instance these terminals formed synaptic contacts onto other targets (Fig. 4A). In GABA-labeled tissue from these animals, BDA-labeled terminals synapsed on dendrites containing gold-silver labeling for GABA alone, as well as dendrites containing both peroxidase labeling for FG or PRV and goldsilver labeling for GABA (Figs. 4C, 5). No terminals synapsed onto dendrites containing only peroxidase labeling for $\mathrm{FG}$ or PRV. These results are summarized in Table 1.

\section{Relationship between BDA-labeled terminals and retrogradely labeled mesoprefrontal dendrites}

Similar to the results obtained in tissue from animals receiving retrograde tracer injections into the NAc, the majority of BDAlabeled terminals in VTA tissue from animals receiving FG injections into the PFC formed synapses onto unlabeled dendrites. In TH-labeled tissue from these animals, BDA-labeled terminals formed synaptic contacts onto dendrites containing only gold-silver labeling for $\mathrm{TH}$, as well as onto dendrites containing both peroxidase labeling for FG and gold-silver labeling for TH (Fig. 6A,B). No terminals synapsed onto dendrites containing only peroxidase labeling for FG. In GABA-labeled tissue, BDA-labeled terminals synapsed onto dendrites containing only gold-silver labeling for GABA or onto dendrites containing only peroxidase labeling for FG (Fig. 6C). No dendrites dually labeled for both GABA and FG received synaptic contact from BDAlabeled terminals. BDA-labeled terminals were observed in the same area of neuropil as dendrites dually labeled for FG and GABA but formed synaptic contacts onto other targets (Fig. 6C). These observations are summarized in Table 1.

\section{DISCUSSION}

This study used a novel triple-labeling method to examine the projection targets and phenotypes of midbrain neurons synapti- 


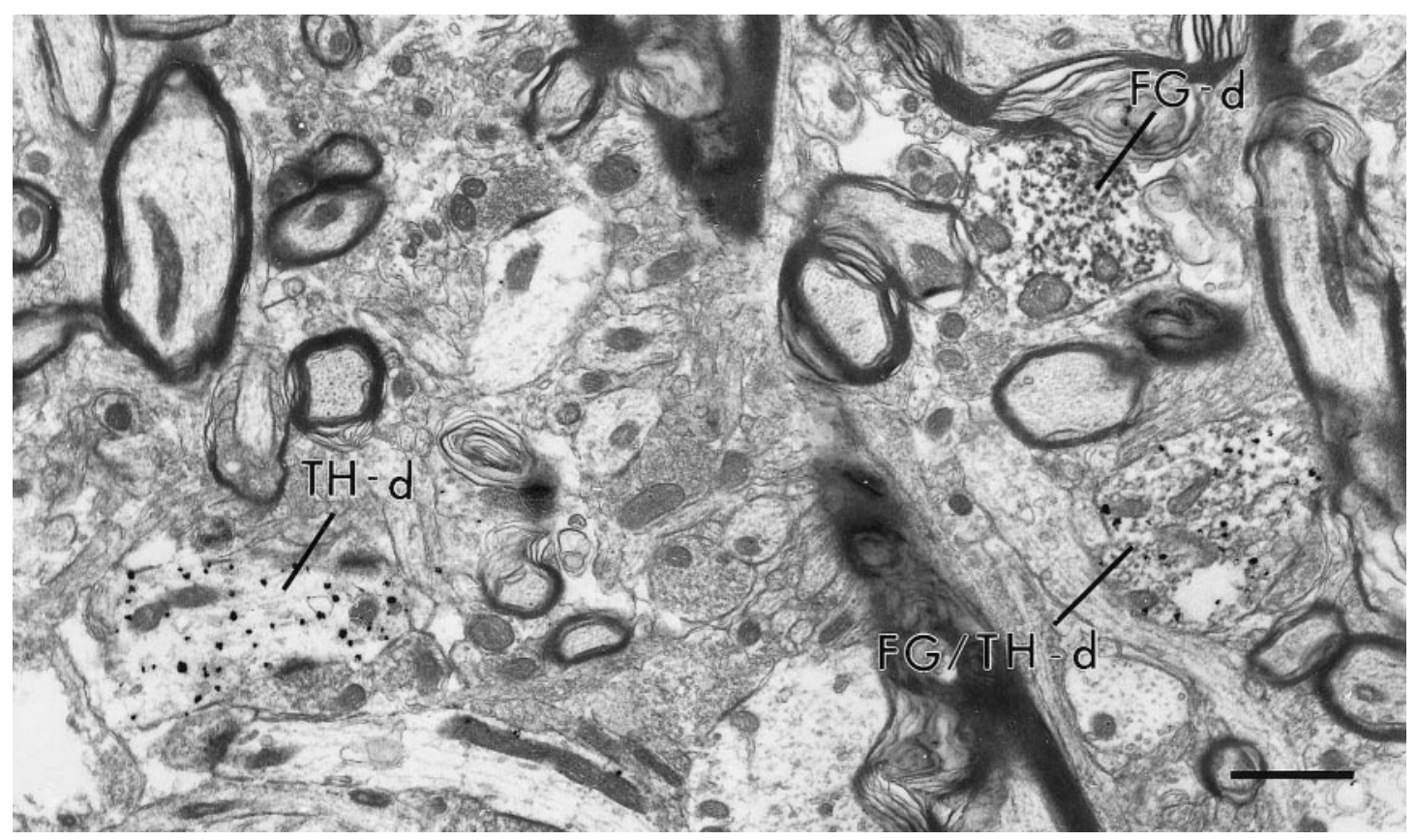

Figure 3. Electron micrograph showing the distribution of immunoperoxidase labeling for FG, retrogradely transported from the NAc, and immunogold-silver labeling for TH within the neuropil of the VTA. A dendrite $(F G / T H-d)$ contains both peroxidase labeling for FG as well as gold-silver labeling for TH. Within the same area of neuropil are dendrites singly labeled for either FG $(F G-d)$ or TH $(T H-d)$. Scale bar, $1.0 \mu \mathrm{m}$.

cally targeted by the PFC. The results demonstrate that PFC terminals selectively synapse onto GABA cells that project to the NAc and DA cells that project to the PFC. These data represent the first direct demonstration of PFC terminals synapsing onto identified populations of DA and GABA neurons within the rat VTA and demonstrate substantial selectivity in the midbrain targets of the PFC. Through these connections, the PFC can mediate a selective influence on the activity of ascending DA and GABA projections. The findings are summarized in Figure 7.

\section{PFC terminals within the VTA}

The observation that PFC terminals formed exclusively asymmetric axodendritic synapses is consistent with previous anatomical observations (Sesack and Pickel, 1992) as well as reports that this pathway mediates an excitatory influence on target cells (Christie et al., 1985; Gariano and Groves, 1988; Murase et al., 1993; Tong et al., 1996, 1998). Approximately one-third (37\%) of PFC terminals synapsed onto TH- immunoreactive VTA dendrites, in close agreement with previous quantitative observations (Sesack and Pickel, 1992). The present study extends these findings by demonstrating that an additional one-third (37\%) of PFC terminals synapse onto GABA-immunoreactive VTA dendrites. It is likely that these $\mathrm{TH}$ - and GABA-labeled dendrites arise from separate neuronal populations, because Kosaka et al. (1987) have reported that $\mathrm{TH}$ and GABA are not colocalized within VTA cells. Although some GABA-labeled cells contacted by PFC terminals were clearly projection neurons, as revealed by retrograde tracing, it is possible that some GABA-labeled dendrites arose from local circuit neurons. Thus, the PFC may alter cell activity within the VTA both by directly synapsing onto projection neurons as well as indirectly via contacts onto interneurons.

In addition to targeting TH- and GABA-labeled dendrites, $26 \%$ of PFC terminals formed asymmetric synapses onto dendrites that contained neither marker. Although this finding may be attributable to inadequate penetration of $\mathrm{TH}$ and GABA antibodies, it is also possible that these dendrites arise from a distinct population of VTA neurons. For example, some cholecystokinin-containing VTA cells do not colocalize DA (Seroogy et al., 1989), and future studies may show that this population receives synaptic $\mathrm{PFC}$ input.

\section{Association of PFC terminals with mesoaccumbens neurons}

The lack of observed synaptic contact of PFC terminals onto TH-labeled mesoaccumbens neurons was contrary to our original hypothesis. Although examples of PFC synaptic contacts onto mesoaccumbens DA cells may have been missed because of limitations inherent in the methods, several observations suggest that a significant innervation of mesoaccumbens DA neurons by PFC terminals was not overlooked. (1) To avoid false-negative results caused by inadequate antibody penetration, our investigation was confined to the Epon-tissue interface where immunolabeling is maximal. (2) The observation that PFC terminals were sometimes in the same area of neuropil as mesoaccumbens THlabeled dendrites confirms that all three markers could be detected within the same area of tissue. (3) PFC terminals synapsed onto TH-labeled neurons that were retrogradely labeled from the PFC. (4) Whereas all the dendrites of every retrogradely labeled neuron might not contain visible tracer in a single section, the findings are strengthened by the observation of comparable results using either FG or PRV to retrogradely label mesoaccumbens neurons. Moreover, we know of no evidence for differential transport of axonal tracers by subclasses of midbrain neurons. (5) Finally, PFC terminals synapsed on GABA-labeled neurons that project to the NAc, despite the fact that these cells represent a minority of the mesoaccumbens projection (Swanson, 1982; Van Bockstaele and Pickel, 1995) and should have been more difficult to observe.

Although the evidence obtained in this study does not support a direct excitatory projection from the PFC to mesoaccumbens 

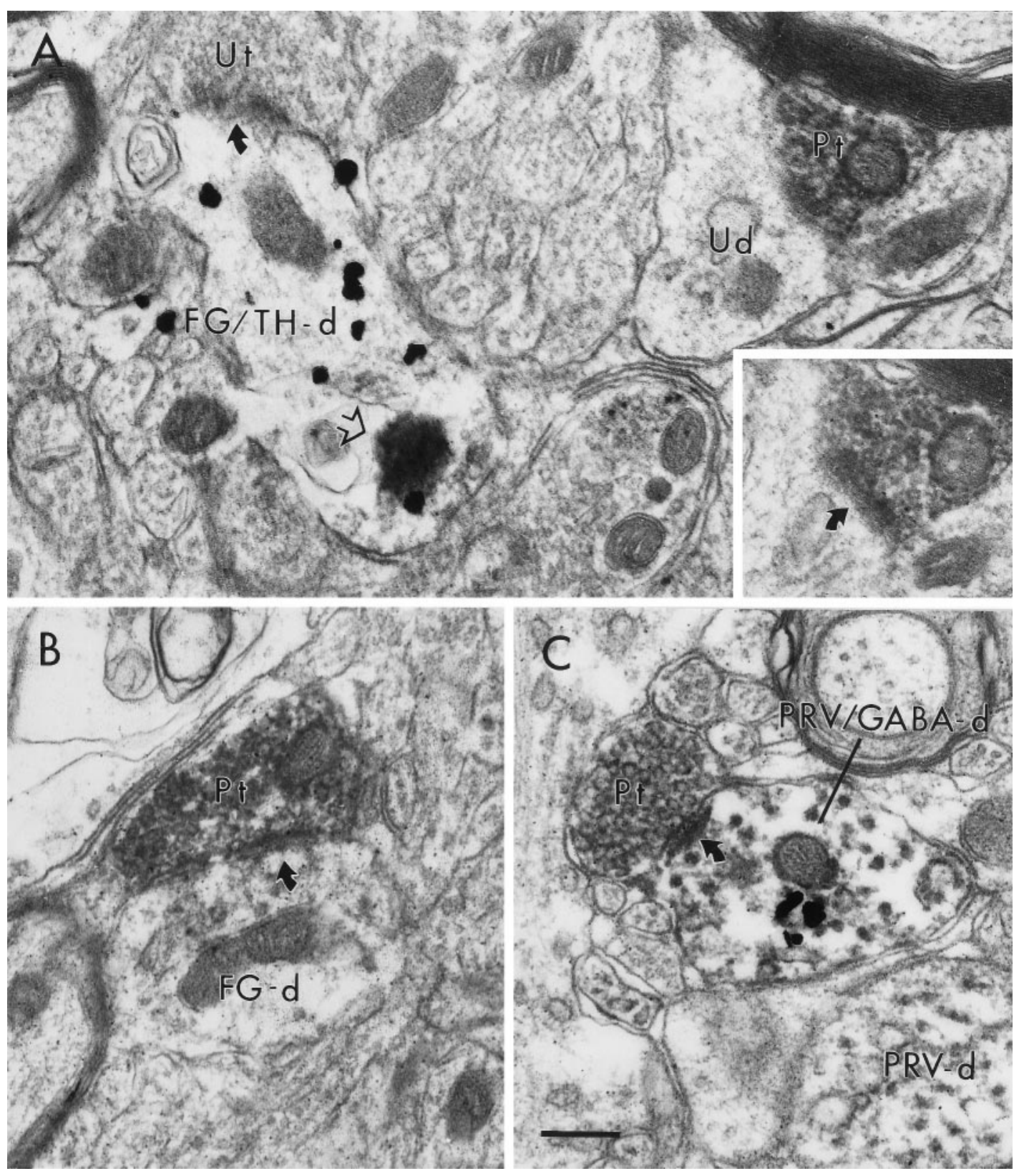

Figure 4. Electron micrographs showing the associations of PFC terminals $(P t)$ with VTA dendrites retrogradely labeled from the NAc. In $A$, a Pt is within the same area of neuropil as a dendrite containing both immunoperoxidase labeling for FG, retrogradely transported from the NAc, as well as immunogold labeling for TH $(F G / T H-d)$. The FG/TH-d exhibits FG labeling concentrated in a lysosome (note flocculent precipitate around the structure at the open arrow) and receives a synaptic contact from an unlabeled terminal (Ut). The Pt does not contact the FG/TH-d but instead contacts an unlabeled dendrite $(U d)$. The oblique synapse (curved arrow) formed by the Pt on the Ud is more evident in an adjacent section (inset). In $B$, a Pt forms a synaptic contact (curved arrow) onto an FG-labeled dendrite $(F G-d)$ that does not contain gold-silver labeling for TH. In $C$, a Pt synapses (curved arrow) on a dendrite $(P R V / G A B A-d)$ that contains both immunoperoxidase labeling for PRV retrogradely transported from the NAc and immunogold-silver labeling for GABA. The PRV/GABA-d is adjacent to a dendrite that contains only peroxidase labeling for PRV $(P R V-d)$. Scale bar, $0.5 \mu \mathrm{m}$.

DA neurons, neurochemical data from several laboratories indicates that the PFC influences DA levels within the NAc (Murase et al., 1993; Taber and Fibiger, 1995; Taber et al., 1995; Karreman and Moghaddam, 1996). This discrepancy can be reconciled if the excitatory effect of PFC stimulation on mesoaccumbens DA cell activity was not produced by a direct projection from the PFC to the VTA but rather by an indirect projection in which the PFC activates another area that, in turn, projects to the VTA. Such an indirect mechanism is consistent with the findings of Tong et al. (1996) that PFC stimulation produces excitatory responses in
VTA cells with a latency inconsistent with a monosynaptic projection. Moreover, such an intermediary is likely to involve a glutamate projection to the VTA, because the effects of PFC stimulation on NAc DA are blocked by glutamate receptor antagonists within the VTA (Taber and Fibiger, 1995; Taber et al., 1995; Karreman and Moghaddam, 1996). The glutamate neurons of the pedunculopontine tegmentum (PPT) are a likely cell group through which the PFC might mediate an indirect excitatory influence on the VTA. The PFC projects to the PPT (Sesack et al., 1989; Hurley et al., 1991), which in turn projects to the VTA 


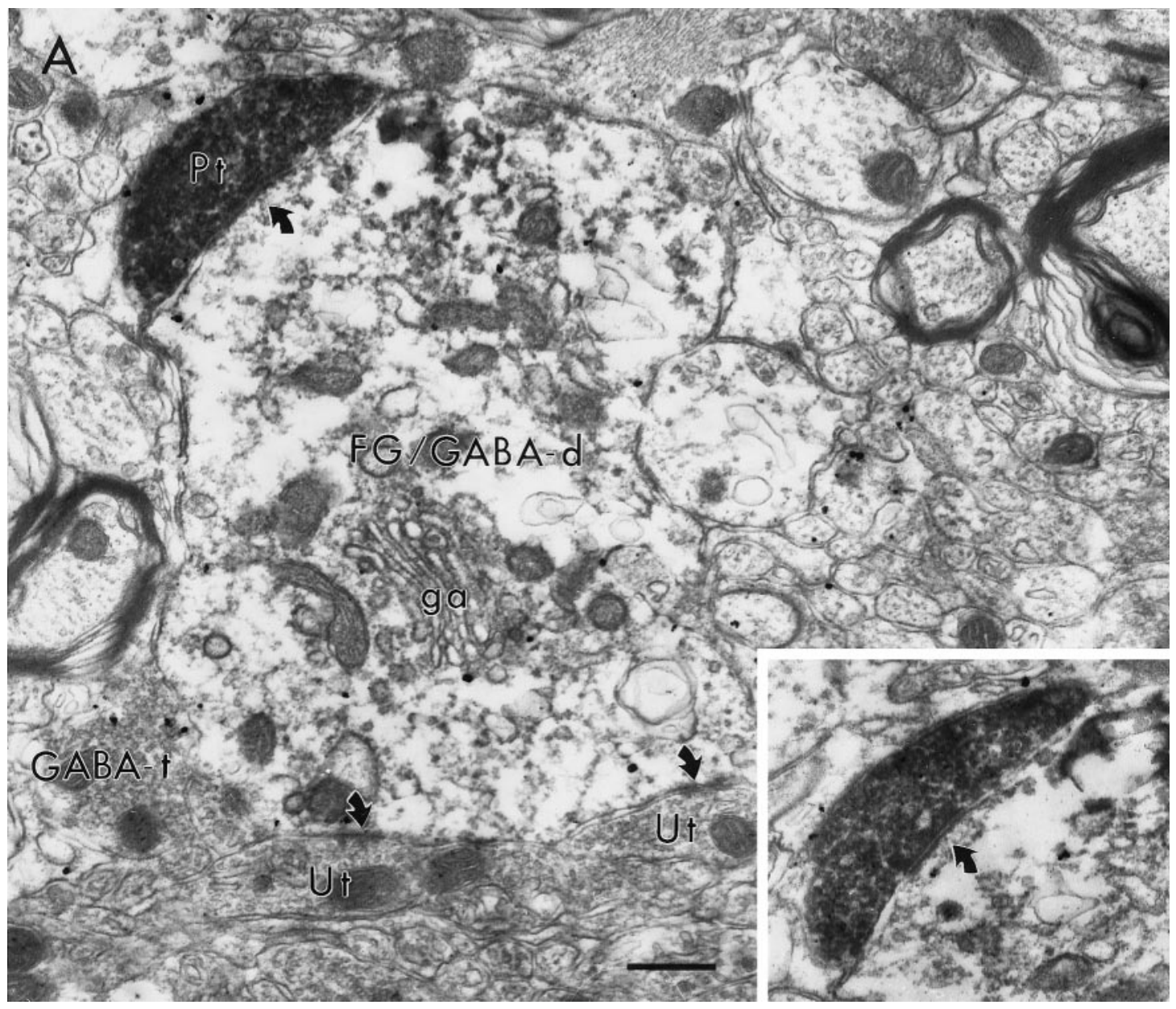

Figure 5. Electron micrographs showing a synaptic contact (curved arrow) of a PFC terminal (Pt) on a dendrite containing both immunoperoxidase labeling for FG retrogradely transported from the NAc and immunogold-silver labeling for GABA $(F G / G A B A-d)$. The postsynaptic dendrite is proximal to the soma, [see Golgi apparatus $(g a)$ ], and receives synaptic input from the Pt (also shown in inset) and from unlabeled terminals (Ut). A GABA-containing terminal (GABA-t) lies adjacent to the dendrite. Scale bar, $0.5 \mu \mathrm{m}$.

(Oakman et al., 1995) and, at least in primates, synapses on DA neurons (Smith et al., 1996). Future examination is required to determine if the excitatory effect of the PFC on mesoaccumbens DA neurons is mediated via the PPT.

The observation of GABA-labeled neurons retrogradely labeled from the NAc is consistent with the report of Van Bockstaele and Pickel (1995) describing a GABA mesoaccumbens projection. We have extended these findings to show that this GABA pathway receives a direct synaptic innervation from the PFC. The functional significance of this circuit is unclear, because little is known about the role of the GABA mesoaccumbens pathway. Van Bockstaele and Pickel (1995) have suggested that this pathway preferentially inhibits the activity of cholinergic local circuit neurons within the NAc. Thus, the excitatory input to these GABA cells could provide a mechanism through which the PFC can indirectly inhibit the activity of NAc cholinergic neurons. Alternatively, if mesoaccumbens GABA neurons synapse onto spiny NAc projection cells, PFC afferents to GABA VTA neurons might exert a feedforward inhibitory influence on NAc output cells. This inhibitory circuit could act in concert with direct excitatory PFC projections to medium spiny neurons (Sesack and Pickel, 1992; O'Donnell and Grace, 1994), with the net effect of exciting some NAc efferent projections while inhibiting others.
It is also possible that PFC synaptic inputs to VTA GABA neurons indirectly regulate mesoaccumbens DA cells through local collaterals. Such an arrangement is consistent with the short-latency inhibition typically evoked in DA neurons by PFC stimulation (Tong et al., 1996). Whereas this inhibition may originate from the basal ganglia, preliminary evidence suggests that VTA GABA neurons regulate DA cell activity (S. Henriksen, personal communication). Future anatomical studies will need to investigate the presence of local connections from GABA cells to mesoaccumbens DA neurons. Such a synaptic organization has important implications for models of schizophrenia pathophysiology (Laruelle et al., 1996; Bertolino et al., 1999), which hypothesize loss of inhibitory control of mesostriatal DA neurons as a result of PFC functional deficits.

\section{Association of PFC terminals with mesoprefrontal neurons}

The finding that PFC terminals synapse onto the dendrites of mesocortical DA neurons is consistent with neurochemical evidence that the infusion of glutamate receptor agonists into the PFC elevates extracellular DA within this cortical area (Jedema and Moghaddam, 1996) and further suggests that this effect may be caused by excitation of the PFC cells that synapse onto mesoprefrontal DA neurons. These results are also consistent with 


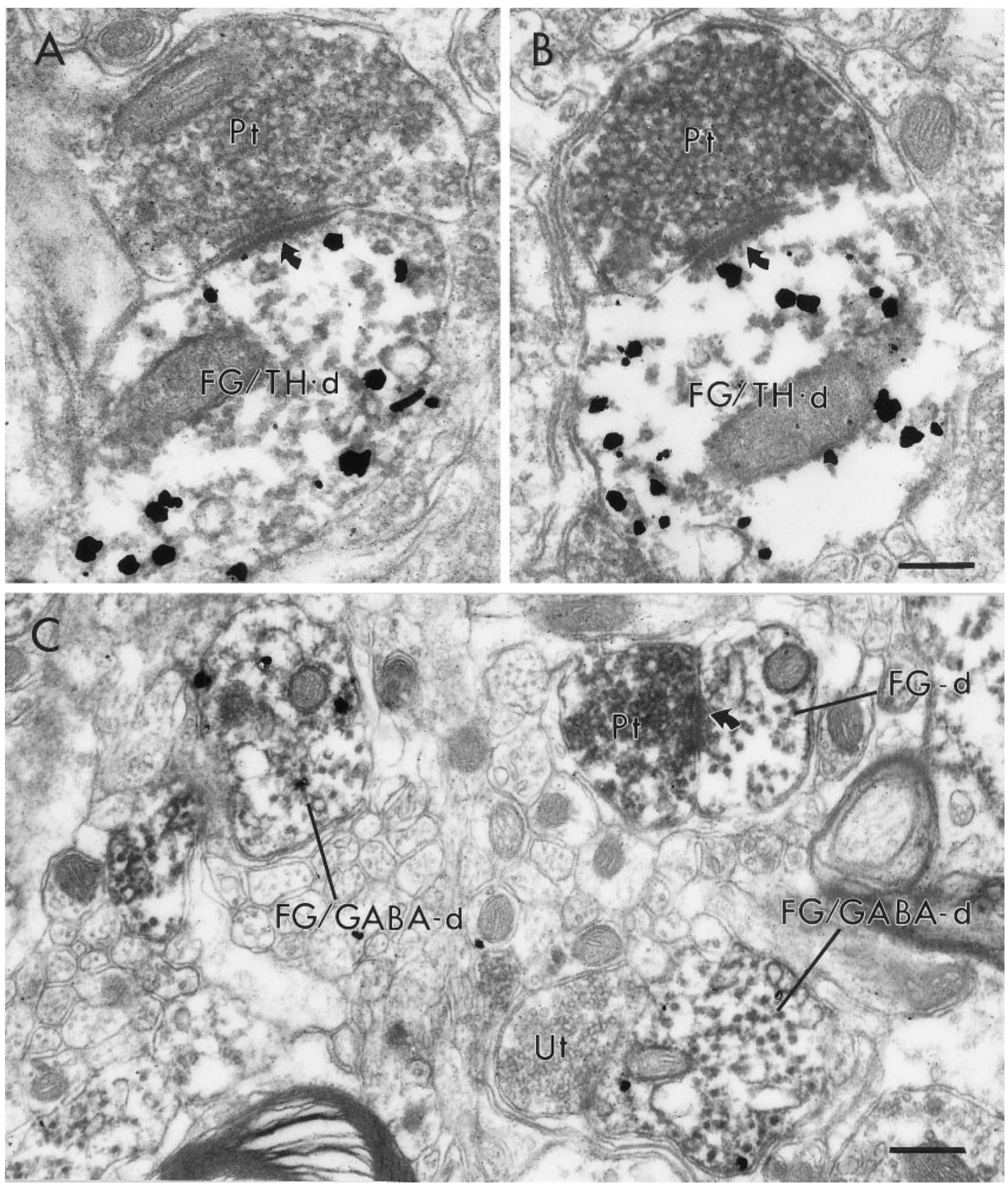

Figure 6. Electron micrographs showing the associations of PFC terminals $(P t)$ with VTA dendrites retrogradely labeled from the PFC. In $A$ and $B$, two different Pts form synaptic contacts (curved arrows) onto dendrites that contain both immunoperoxidase labeling for FG retrogradely transported from the PFC as well as immunogold-silver labeling for TH $(F G / T H-d)$. In $C$, a Pt synapses on a dendrite $(F G-d)$ that contains retrogradely transported FG but does not contain gold-silver labeling for GABA. Within the same area of neuropil, two other dendrites $(F G / G A B A-d)$ contain both markers. One FG/GABA-d is apposed to an unlabeled terminal $(U t)$. Scale bar, $0.25 \mu \mathrm{m}$.

electrophysiological data that PFC stimulation produces a shortlatency response in DA cells antidromically activated from the PFC (Thierry et al., 1979; Gariano and Groves, 1988). This reciprocal projection may mediate an inhibitory feedback mechanism because most in vivo studies report that DA suppresses PFC cell activity (Thierry et al., 1988; Sesack and Bunney, 1989). This projection may also play a role in the unique response of this pathway to stress (Horger and Roth, 1996), because both PFC cells (Mantz et al., 1988) and mesocortical DA neurons (Thierry et al., 1976; Mantz et al., 1989; Deutch et al., 1991) are activated by stressful stimuli. Finally, the finding of synaptic input from prefrontal association cortex to mesocortical DA neurons has important significance for understanding the role of DA in facilitating learning by the communication of future expectations (Schultz, 1997).

In addition to the well-characterized DA projection to the PFC, the VTA also sends a substantial GABA projection to this area, comprising $58 \%$ of all mesoprefrontal neurons (Carr and Sesack, 2000). Within the PFC, VTA GABA terminals synapse on both pyramidal cells and GABA local circuit neurons and are thus positioned to mediate both direct inhibitory and indirect disinhibitory influences. The observation that mesoprefrontal GABA neurons did not receive synaptic innervation from the PFC suggests that this pathway does not participate in a direct feedback 


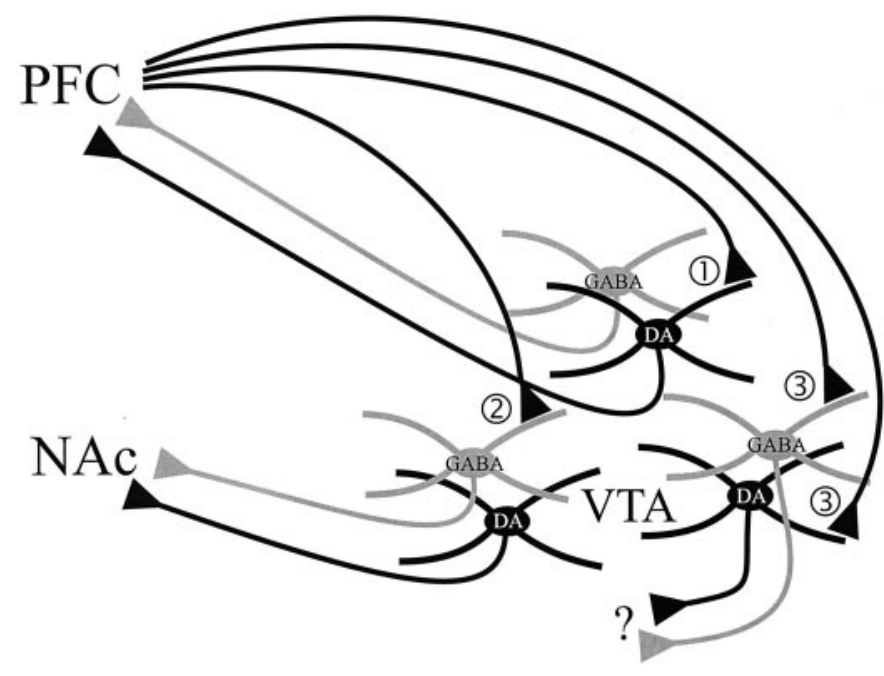

Figure 7. Schematic drawing of the observed relationships between PFC terminals and mesoprefrontal, mesoaccumbens, and other projection neurons of the VTA. 1, A small population of PFC terminals form synaptic contacts onto DA neurons that project to the PFC. 2, Another population of PFC terminals synapse onto GABA neurons that project to the NAc. 3, The majority of PFC terminals within the VTA appear to target DA and GABA neurons that project to unknown target sites. It is also possible that PFC terminals project onto VTA neurons that contain neither DA nor GABA.

mechanism. It is possible that a minor input from the PFC to GABA mesocortical cells was overlooked. However, many of the same arguments as provided for the mesoaccumbens DA cells are also applicable here. In particular, PFC terminals synapsed on mesoprefrontal DA neurons, despite the fact that these cells make up a minority of the projection population (Swanson, 1982; Carr and Sesack, 2000) and should have been more difficult to detect than GABA-labeled neurons. Future studies are necessary to understand the sources of afferent input that drive activity in the newly discovered GABA mesocortical pathway.

In tissue from animals receiving retrograde tracer injections into either the PFC or the NAc, most PFC terminals formed synaptic contacts onto $\mathrm{TH}$ - or GABA-labeled neurons that were not retrogradely labeled. It is thus likely that PFC terminals also target VTA cells that project to other regions, although the projection targets of these neurons are not known. Based on previous studies of the distribution of VTA projection neurons, as well as the terminal field of PFC axons within the VTA, other likely targets are the septum, amygdala, or entorhinal cortex (Swanson, 1982). Future investigation is required to identify the other efferent populations of VTA neurons that are synaptically driven by the PFC.

\section{Conclusions}

The findings of this study that PFC terminals synapse selectively onto mesoaccumbens GABA neurons and mesoprefrontal DA neurons were unexpected. Given that $\sim 80 \%$ of the VTA projection to the NAc contains DA (Swanson, 1982) and $\sim 60 \%$ of mesoprefrontal cells contain GABA (Carr and Sesack, 2000), one would expect that these two populations would have the highest probability of receiving PFC synaptic contacts. The observation that in both systems, PFC terminals target the cell population that makes up the minority of the overall projection (GABA projections to the NAc and DA projections to the PFC) strongly suggests that the synaptic contacts of PFC terminals within the VTA are not randomly distributed but are targeted to specific cell populations. Thus, despite the relatively low density of PFC terminals within the VTA (Sesack and Pickel, 1992), the functional influence of this pathway may be enhanced by selective targeting of specific neuronal populations.

\section{REFERENCES}

Bassareo V, Di Chiara G (1997) Differential influence of associative and nonassociative learning mechanisms on the responsiveness of prefrontal and accumbal dopamine transmission to food stimuli in rats fed $\mathrm{ad}$ libitum. J Neurosci 17:851-861.

Bean AJ, Roth RH (1991) Extracellular dopamine and neurotensin in rat prefrontal cortex in vivo: effects of median forebrain bundle stimulation frequency, stimulation pattern, and dopamine autoreceptors. J Neurosci 11:2694-2702.

Bertolino A, Knable MB, Saunders RC, Callicott JH, Kolachana B, Mattay VS, Bachevalier J, Frank JA, Egan M, Weinberger DR (1999) The relationship between dorsolateral prefrontal $N$-acetylaspartate measures and striatal dopamine activity in schizophrenia. Biol Psychiatry 45:660-667.

Card JP, Levitt P, Enquist LW (1998) Different patterns of neuronal infection after intracerebral injection of two strains of pseudorabies virus. J Virol 72:4434-4441.

Carr DB, O’Donnell P, Card JP, Sesack SR (1999) Dopamine terminals in the rat prefrontal cortex synapse on pyramidal cells that project to the nucleus accumbens. J Neurosci 19:11049-11060.

Carr DB, Sesack SR (2000) GABA-containing neurons in the rat ventral tegmental area project to the prefrontal cortex. Synapse In Press.

Charlety PJ, Grenhoff J, Cherugi K, De La Chapelle B, Buda M, Svensson TH, Chouvet G (1991) Burst firing of mesencephalic dopamine neurons is inhibited by somatodendritic application of kynurenate. Acta Physiol Scand 142:105-112.

Chergui K, Charlety PJ, Akaoka H, Saunier CF, Brunet J-L, Svensson TH, Chouvet G (1993) Tonic activation of NMDA receptors causes spontaneous burst discharge of rat midbrain dopamine neurons in vivo. Eur J Neurosci 5:137-144.

Christie MJ, Bridge S, James LB, Beart PM (1985) Excitotoxin lesions suggest an aspartatergic projection from rat medial prefrontal cortex to ventral tegmental area. Brain Res 333:169-172.

Deutch AY, Lee MC, Gillham MH, Cameron D, Goldstein M, Iadorola MJ (1991) Stress selectively increases Fos protein in dopamine neurons innervating the prefrontal cortex. Cereb Cortex 1:273-292.

Finlay JM, Zigmond MJ, Abercrombie ED (1995) Increased dopamine and norepinephrine release in medial prefrontal cortex induced by acute and chronic stress: effects of diazepam. Neuroscience 64:619-628.

Gariano RF, Groves PM (1988) Burst firing induced in midbrain dopamine neurons by stimulation of the medial prefrontal and anterior cingulate cortices. Brain Res 462:194-198.

Gonon FG (1988) Nonlinear relationship between impulse flow and dopamine released by rat midbrain dopaminergic neurons as studied by in vivo electrochemistry. Neuroscience 24:19-28.

Grace AA (1987) The regulation of dopamine neuron activity as determined by in vivo and in vitro intracellular recordings. In: Neurophysiology of dopamine systems: current status and clinical perspectives (Chiodo LA, Freeman AS, eds), pp 1-66. Grosse Pointe: Lakeshore.

Grace AA (1988) In vivo and in vitro intracellular recordings from rat midbrain dopamine neurons. Annals of the New York Academy of Sciences 537:51-76.

Gray EG (1959) Axo-somatic and axo-dendritic synapses of the cerebral cortex: an electron microscope study. J Anatomy 93:420-433.

Grenhoff J, Tung C-S, Svensson TH (1988) The excitatory amino acid antagonist kynurenate induces pacemaker-like firing of dopamine neurons in rat ventral tegmental area in vivo. Acta Physiol Scand 134:567-568.

Horger BA, Roth RH (1996) The role of mesoprefrontal dopamine neurons in stress. Crit Rev Neurobiol 10:395-418.

Hurley KM, Herbert H, Moga MM, Saper CB (1991) Efferent projections of the infralimbic cortex of the rat. J Comp Neurol 308:249-276.

Jedema HP, Moghaddam B (1996) Characterization of excitatory amino acid modulation of dopamine release in the prefrontal cortex of conscious rats. J Neurochem 66:1448-1453.

Karreman M, Moghaddam B (1996) The prefrontal cortex regulates the 
basal release of dopamine in the limbic striatum: an effect mediated by ventral tegmental area. J Neurochem 66:589-598.

Kosaka T, Kosaka K, Hataguchi Y, Nagatsu I, Wu JY, Ottersen OP, Storm-Mathisen J, Hama K (1987) Catecholaminergic neurons containing GABA-like and/or glutamic acid decarboxylase-like immunoreactivities in various brain regions of the rat. Exp Brain Res 66:191-210.

Laruelle M, Abi-Dargham A, van Dyck CH, Gil R, D'Souza CD, Erdos J, McCance E, Rosenblatt W, Fingado C, Zoghbi SS, Baldwin RM, Seibyl JP, Krystal JH, Charney DS, Innis RB (1996) Single photon emission computerized tomography imaging of amphetamine-induced dopamine release in drug-free schizophrenic subjects. Proc Natl Acad Sci USA 93:9235-9240.

Leak RK, Card JP, Moore RY (1999) Suprachiasmatic pacemaker organization analyzed by viral transynaptic transport. Brain Res 819:23-32.

Leranth C, Pickel VM (1989) Electron microscopic preembedding double-immunostaining methods. In: Neuroanatomical tract tracing methods 2: recent progress (Heimer L, Záborszky L, eds), pp 129-172. New York: Plenum.

Lu X-Y, Churchill L, Kalivas PW (1997) Expression of $D_{1}$ receptor mRNA in projections from the forebrain to the ventral tegmental area. Synapse 25:205-214.

Mantz J, Millla C, Glowinski J, Thierry A-M (1988) Differential effects of ascending neurons containing dopamine and noradrenaline in control of spontaneous activity and of evoked responses in the rat prefrontal cortex. Neuroscience 27:517-526.

Mantz J, Thierry A-M, Glowinski J (1989) Effects of noxious tail pinch on the discharge rate of mesocortical and mesolimbic dopamine neurons: selective activation of the mesocortical system. Brain Res 476:377-381.

Murase S, Grenhoff J, Chouvet G, Gonon FG, Svensson TH (1993) Prefrontal cortex regulates burst firing and transmitter release in rat mesolimbic dopamine neurons studied in vivo. Neurosci Lett 157:53-56.

Oakman SA, Faris PL, Kerr PE, Cozzari C, Hartman BK (1995) Distribution of pontomesencephalic cholinergic neurons projecting to substantia nigra differs significantly from those projecting to ventral tegmental area. J Neurosci 15:5859-5869.

O'Donnell P, Grace AA (1994) Tonic $\mathrm{D}_{2}$-mediated attenuation of cortical excitation in nucleus accumbens neurons recorded in vitro. Brain Res 634:105-112.

O’Donnell P, Lavin A, Enquist LW, Grace AA, Card JP (1997) Interconnected parallel circuits between rat nucleus accumbens and thalamus revealed by retrograde transynaptic transport of pseudorabies virus. J Neurosci 17:2143-2167.

Overton P, Clark D (1992) Iontophoretically administered drugs acting at the $\mathrm{N}$-methyl-D-aspartate receptor modulate burst firing in A9 dopamine neurons in the rat. Synapse 10:131-140.

Paxinos G, Watson C (1986) The rat brain in stereotaxic coordinates. New York: Academic.

Peters A, Palay SL, Webster H (1991) The fine structure of the nervous system: neurons and their supporting cells, Ed 3. New York: Oxford.

Pieribone VA, Aston-Jones G (1988) The iontophoretic application of Fluoro-Gold for the study of afferents to deep brain nuclei. Brain Res 475:259-271.

Rebec GV, Grabner CP, Johnson M, Pierce RC, Bardo MT (1997) Transient increases in catecholaminergic activity in medial prefrontal cortex and nucleus accumbens shell during novelty. Neuroscience 76:707-714.

Schultz W (1997) Dopamine neurons and their role in reward mechanisms. Curr Opin Neurobiol 7:191-197.

Schultz W, Dayan P, Montague PR (1997) A neural substrate of prediction and reward. Science 275:1593-1599.
Seroogy KB, Dangaran K, Lim S, Haycock JW, Fallon JH (1989) Ventral mesencephalic neurons containing both cholecystokinin- and tyrosine hydroxylase-like immunoreactivities project to forebrain regions. J Comp Neurol 279:397-414.

Sesack SR, Bunney BS (1989) Pharmacological characterization of the receptor mediating electrophysiological responses to dopamine in the rat medial prefrontal cortex: a microiontophoretic study. J Pharmacol Exp Ther 248:1323-1333.

Sesack SR, Pickel VM (1992) Prefrontal cortical efferents in the rat synapse on unlabeled neuronal targets of catecholamine terminals in the nucleus accumbens septi and on dopamine neurons in the ventral tegmental area. J Comp Neurol 320:145-160.

Sesack SR, Deutch AY, Roth RH, Bunney BS (1989) Topographical organization of the efferent projections of the medial prefrontal cortex in the rat: an anterograde tract-tracing study with Phaseolus vulgaris leucoagglutinin. J Comp Neurol 290:213-242.

Smith Y, Charara A, Parent A (1996) Glutamatergic inputs from the pedunculopontine nucleus to midbrain dopaminergic neurons in primates: phaseolus vulgaris-leucoagglutinin anterograde labeling combined with postembedding glutamate and GABA immunohistochemistry. J Comp Neurol 364:254-266.

Streckler RL, Jacobs BL (1987) Dopaminergic unit activity during behavior. In: Neurophysiology of dopamine systems: current status and clinical perspectives (Chiodo LA, Freeman AS, eds), pp 165-185. Grosse Pointe: Lakeshore.

Svensson T, Tung C-S (1989) Local cooling of pre-frontal cortex induces pacemaker-like firing of dopamine neurons in rat ventral tegmental area in vivo. Acta Physiol Scand 136:135-136.

Swanson LW (1982) The projections of the ventral tegmental area and adjacent regions: a combined fluorescent retrograde tracer and immunofluorescence study in the rat. Brain Res Bull 9:321-353.

Taber MT, Fibiger HC (1995) Electrical stimulation of the prefrontal cortex increases dopamine release in the nucleus accumbens of the rat: modulation by metabotropic glutamate receptors. J Neurosci 15:3896-3904.

Taber MT, Das S, Fibiger HC (1995) Cortical regulation of subcortical dopamine release: mediation via the ventral tegmental area. J Neurochem 65:1407-1410.

Takahata R, Moghaddam B (1998) Glutamatergic regulation of basal and stimulus-activated dopamine release in the prefrontal cortex. J Neurochem 71:1443-1449.

Thierry A-M, Tassin JP, Blanc G, Glowinski J (1976) Selective activation of the mesocortical DA system by stress. Nature 263:242-244.

Thierry A-M, Deniau JM, Feger J (1979) Effects of stimulation of the frontal cortex on identified output VMT cells in the rat. Neurosci Lett 15:103-107.

Thierry A-M, Milla MC, Glowinski J (1988) Influence of the mesocortical/prefrontal dopamine neurons on their target cells. Ann NY Acad Sci 537:101-111.

Tong Z-Y, Overton PG, Clark D (1996) Stimulation of the prefrontal cortex in the rat induces patterns of activity in midbrain dopaminergic neurons which resemble natural burst events. Synapse 22:195-208.

Tong Z-Y, Overton PG, Martinezcue C, Clark D (1998) Do nondopaminergic neurons in the ventral tegmental area play a role in the responses elicited in A10 dopaminergic neurons by electrical stimulation of the prefrontal cortex. Exp Brain Res 118:466-476.

Van Bockstaele EJ, Pickel VM (1995) GABA-containing neurons in the ventral tegmental area project to nucleus accumbens in rat brain. Brain Res 682:215-221.

Westerink BHC (1995) Brain microdialysis and its application for the study of animal behavior. Behav Brain Res 70:103-124.

Wilson C, Nomikos GG, Collu M, Fibiger HC (1995) Dopaminergic correlates of motivated behavior: importance of drive. J Neurosci 15:5169-5178. 